\title{
Analytical Modelling of a Spray Column Three-Phase Direct Contact Heat Exchanger
}

\author{
Hameed B. Mahood, ${ }^{1,2}$ Adel O. Sharif, ${ }^{1}$ Seyed Ali Hosseini, ${ }^{1}$ and Rex B. Thorpe ${ }^{1}$ \\ ${ }^{1}$ Centre for Osmosis Research and Applications (CORA), Chemical and Process Engineering Department, Faculty of Engineering and \\ Physical Sciences, University of Surrey, Guildford GU2 7XH, UK \\ ${ }^{2}$ University of Misan, Misan, Iraq \\ Correspondence should be addressed to Hameed B. Mahood; hbmahood@yahoo.com
}

Received 20 December 2012; Accepted 26 January 2013

Academic Editors: F. Banat, K. Okumura, and E. Sahle-Demessie

Copyright (C) 2013 Hameed B. Mahood et al. This is an open access article distributed under the Creative Commons Attribution License, which permits unrestricted use, distribution, and reproduction in any medium, provided the original work is properly cited.

\begin{abstract}
An analytical model for the temperature distribution of a spray column, three-phase direct contact heat exchanger is developed. So far there were only numerical models available for this process; however to understand the dynamic behaviour of these systems, characteristic models are required. In this work, using cell model configuration and irrotational potential flow approximation characteristic models has been developed for the relative velocity and the drag coefficient of the evaporation swarm of drops in an immiscible liquid, using a convective heat transfer coefficient of those drops included the drop interaction effect, which derived by authors already. Moreover, one-dimensional energy equation was formulated involving the direct contact heat transfer coefficient, the holdup ratio, the drop radius, the relative velocity, and the physical phases properties. In addition, time-dependent drops sizes were taken into account as a function of vaporization ratio inside the drops, while a constant holdup ratio along the column was assumed. Furthermore, the model correlated well against experimental data.
\end{abstract}

\section{Introduction}

A direct contact heat exchanger is a highly effective device for transferring heat between two immiscible fluids while they are flowing co-currently or countercurrently inside a column. The main feature of the direct contact heat exchanger is that it permits a confident contact between a hot fluid and a cold fluid. However, a number of different methods have been used to define the type of direct contact heat exchanger, including layer type, where the hot fluid is stagnant while the cold fluid flows on top, and a spray type, where one of two fluids is injected into the other. Generally, there are two types of spray column, depending on which injection technique is being used: an integrated type and a split type. In the former, the cold fluid is dispersed from the bottom of the column into a hot fluid, whereas in the second one, the hot fluid is pumped in countercurrently with the flowing cold fluid [1].

A direct contact heat exchanger has several advantages over surface heat exchangers [2], such as eliminating metallic heat transfer surface between fluids which are prone to corrosion and fouling, as well as increasing the heat transfer resistance. It can be operated at very low temperature differences or heat transfer driving forces and allows lower mass flow rates of transferring fluids, convenient separation of the fluids, and a high heat transfer coefficient (about 20-100 times than single phase or surface type heat exchanger) [3]. Therefore, it can be found in several industrial applications, such as water desalination by freezing, geothermal power energy production, crystallization, waste heat recovery, energy storage systems, solar power energy, and emergency cooling of chemical and nuclear reactors [4]. Considerable attention has been paid to the area of direct contact heat exchangers in recent years, particularly when change of phase takes place, but most of the efforts have been focused on the evaporation of single drops or condensation of single bubbles.

A very limited number of experimental, theoretical, and numerical investigations have dealt with the evaporation of multidrops in an immiscible liquid media. In addition, the available works in this area have concentrated mainly on single parameters affecting the phenomena of heat transfer 
in direct contact heat exchangers, such as a heat transfer coefficient and holdup ratio. Sideman and Gat [5] studied experimentally the operating characteristics of a spray column using a pentane-water system and calculated the volumetric heat transfer coefficient and average holdup ratio as a function of pentane and water superficial velocities. The temperature profiles of the dispersed (kerosene) and continuous phases (water) in a spray-column direct contact heat exchanger, were investigated both experimentally and theoretically by Letan and Kehat [6]. They proposed that the mechanism of heat transfer inside the spray column could be characterized by five regions: wake growth, intermediate, continuous wake shedding, mixing, and coalesce regimes, respectively. In addition, they observed that the heat exchange between the two phases in both heating and cooling processes occurs only in the certain zones wake growth, continuous wake shedding, and mixing region. The characteristics of the liquid-liquid spray-column direct contact heat exchanger were studied by Plass et al. [7] experimentally. The volumetric heat transfer coefficient was found and they correlated their experimental results of volumetric heat transfer as a function of holdup ratio. By using a numerical technique Coban and Boehm [8], Jacobs and Golafshani [9] and Brickman and Boehm [10] developed a one-dimensional numerical model to study the flow and the heat transfer of a spray column direct contact heat exchanger. The mass, momentum, and energy equations of two-component two-phase flow were solved and the temperature profile, total heat transfer, and holdup ratio were calculated. Several heat transfer models for interfacial heat transfer between the dispersed and continuous phases were examined by [9] and they found that the conduction controlled heat transfer is dominated by small diameter liquid drops. While, the possibility of increasing a spray column direct contact heat transfer output was included in the analysis of Brickman and Boehm [10]. They found that decreasing the dispersed phase inlet temperature while maintain a continuous phase inlet temperature produced an increase of $10-20 \%$ in heat transfer inside the column. Also, the optimum conditions can be achieved when using the dispersed phase at or very near to its saturation temperature. The effect of the superficial velocity and the initial temperature of the continuous phase and the dispersed phase on the volumetric heat transfer coefficient of an n-pentane-water, three-phase, direct-contact heat exchanger were investigated by Peng et al. [3] experimentally and theoretically. Their results indicated that the volumetric heat transfer coefficient increases with increasing initial temperature and superficial velocity of continuous phase, while the superficial dispersed phase velocity had no effect. More accurate numerical model is carried out by Kang et al. [11] to study the heat transfer characteristics of a spray column direct contact heat exchanger. A twodimensional axisymmetric two-component flow model was developed and they found the injection velocity of dispersed phase has a dominated effect more than other parameters and the volumetric heat transfer coefficient is uniform until the middle column is reached.

So far there were only numerical models available which deal with the direct contact heat transfer process in a spray column direct contact heat exchanger; however to understand the dynamic behaviour of these systems, characteristic models are required. In this investigation, an analytical model is developed to study the characteristic heat transfer of a spray-column direct contact heat exchanger. The analysis is based on solving the one-dimensional energy equation for two-component two-phase flow using a cell model. The direct contact heat transfer coefficient, drag coefficient, and relative velocity of multidrops' evaporation during their flow in the countercurrent with hot water were determined and the temperature distribution along the column height was found. It is important here to note that no analytical model is currently available to describe the temperature distribution of the temperature inside the direct contact column.

\section{Theoretical Modelling}

Initially, due to the large diameter of the column in comparison to the diameter of the drops, and because there is no circulation zone inside the column, the flow inside the column can be assumed to be a one-dimensional flow [9]. On the other hand, immiscibility between the countercurrent flow phases means the mass flow rate of both phases stays constant along the column because neither the dispersed phase or the continuous phasen goes into solution in the other phase.

The continuity equations for countercurrent flow of the phases can be written as [8]

$$
\begin{gathered}
\dot{m}_{d}=\rho_{d} A \alpha U_{d}, \\
\dot{m}_{c}=\rho_{c} A(1-\alpha) U_{c} .
\end{gathered}
$$

For one-dimensional, steady-state flow, the energy equations for both phases can be written as

$$
\begin{gathered}
\frac{d}{d z}\left[\rho_{d} \alpha U_{d} H_{d}\right]=-\frac{Q}{V}, \\
\frac{d}{d z}\left[\rho_{c}(1-\alpha) U_{c} H_{c}\right]=\frac{\eta Q}{V} .
\end{gathered}
$$

Substituting (1) and (2) into (3) and (4), respectively, yields

$$
\begin{aligned}
& \frac{d H_{d}}{d z}=-\frac{A}{\dot{m}_{d}} \frac{Q}{V}, \\
& \frac{d H_{c}}{d z}=\frac{A}{\dot{m}_{c}} \frac{\eta Q}{V},
\end{aligned}
$$

where $\mathrm{Q}$ represents the heat transfer from the continuous phase to the dispersed phase and $\eta$ denotes the ratio of the heat transfer from the continuous phase divided by the heat transfer to the dispersed phase, when no heat is lost to the surroundings:

$$
\eta=1
$$


Equations (5) and (6) can be written in terms of the phase temperature, as:

$$
\begin{aligned}
& \frac{d T_{c}}{d z}=-\frac{Q}{\dot{m}_{c} c_{p c}} \frac{A}{V}, \\
& \frac{d T_{d}}{d z}=\frac{Q}{\dot{m}_{d} c_{p d}} \frac{A}{V},
\end{aligned}
$$

where

$$
\begin{aligned}
& H_{c}=c_{p c} T_{c}, \\
& H_{d}=c_{p d} T_{d},
\end{aligned}
$$

where $H_{d}$ and $H_{c}$ denote the enthalpies of the dispersed phase and the continuous phase, respectively, and $(A / V)$ is the total heat transfer area per unit volume. Plass et al. [7] suggested the following expression for this parameter and for spherical drops:

$$
\frac{A}{V}=\frac{6 \alpha}{d}
$$

where $\alpha$ denoted the holdup ratio or the ratio between the volumes of dispersed phase in the column and the total volume (dispersed and continuous phase volume) and $d$ is the column diameter.

Substituting (11) into (8) and (9) results in

$$
\begin{aligned}
& \frac{d T_{c}}{d z}=-\left(\frac{6 \alpha}{d}\right) \frac{Q}{\dot{m}_{c} c_{p c}}, \\
& \frac{d T_{d}}{d z}=\left(\frac{6 \alpha}{d}\right) \frac{Q}{\dot{m}_{d} c_{p c}} .
\end{aligned}
$$

The heat transfer from the continuous phase to the dispersed phase $Q$ can be found as

$$
Q=h A \Delta T
$$

where $h$ is the direct contact heat transfer coefficient. Brikman and Boehm [10] and others used the heat transfer coefficient for a single evaporation drop and multiplied it by the number of drops to include the void fraction in their analysis. However, it is more useful to use an expression for heat transfer coefficient related to the multidrops or holdup ratio inside the column. Actually, the phenomenon of heat transfer to the droplets, including the droplet phase change, is quite complex due to coalescing or breaking down of the droplets along the column height. In addition, droplet shapes might change due to evaporation from spherical to ellipsoidal and finally to spherical-cup shapes. Therefore, an assumption should be made to allow simplification of the complexity of such phenomena. To this end, it is useful to assume that the droplets remain spherical along the direct contact heat transfer process, and no coalescing nor breaking down occurs for the evaporation droplets and finally that there is a constant droplet number.

Assume the droplets swarm to be spherical in shape and that they move in potential flow fields with a constant drop radius, and by solving the steady-state energy equation for the spherical coordinate using a potential flow configuration for the velocity components, and a cell model assumption, Mahood (2012) [12] has found the heat transfer coefficient in terms of $\mathrm{Nu}$ number, for the multidrops evaporation in an immiscible liquid as

$$
\mathrm{Nu}=\frac{4}{\sqrt{6 \pi}} \cdot\left(\frac{\alpha+0.5}{1-\alpha}\right)^{0.5} \cdot \mathrm{Pe}^{0.5} .
$$

The convective heat transfer coefficient in (15) was derived by solving a steady-state energy equation in spherical coordinates, which involved velocity components. These components of the velocity were found from the solution for the potential flow field around the two-phase bubbles. Because no viscous or actual solution dealing with the evaporation of the two-phase bubble is available to compare with the potential flow solution, Isenberg and Sideman [13], Moalem et al. [14], and Moalem et al. [15] used the flowing velocity factor, in which the solution is based on the assumption that the potential flow is converted to an actual or viscous solution:

$$
k_{v}=0.25 \operatorname{Pr}^{-1 / 3},
$$

and for pure potential flow

$$
k_{v}=1 .
$$

Therefore, (15) becomes:

$$
\mathrm{Nu}=\frac{4}{\sqrt{6 \pi}} \cdot\left(\frac{\alpha+0.5}{1-\alpha} k_{v}\right)^{0.5} \mathrm{Pe}^{0.5} .
$$

The heat transfer coefficient is related to the slip or relative velocity of the two phases in the column, so it is important to derive the relative velocity expression for the countercurrent two-phase flow inside the column.

Using a cell model as shown in Figure 1, the potential velocity of the drops in the swarm was given by MilneThomson [16] and used by Cai and Wallis [17] as follows:

$$
\phi=\frac{\cos \theta}{b^{3}-a^{3}}\left[\left(a^{3} U-b^{3} v\right) r+\frac{a^{3} b^{3}}{2 r^{2}}(U-v)\right],
$$

where $U$ and $v$ are represented velocity of inner and outer cell boundaries, respectively.

For $v=0,(19)$ reduces to the expression given by Lamb [18] and used by Kendoush [19] as

$$
\phi=\frac{U}{b^{3}-a^{3}}\left[a^{3} r+\frac{a^{3} b^{3}}{2 r^{2}}\right] \cos \theta .
$$

And for $\alpha=(a / b)^{3},(20)$ becomes:

$$
\phi=\frac{U}{(1-\alpha)}\left[\alpha r+\frac{1}{2}\left(\frac{a^{3}}{r^{2}}\right)\right] \cos \theta .
$$

The velocity components of potential flow can be found using (21) as

$$
\begin{gathered}
V_{r}=-\frac{\partial \phi}{\partial r}=\frac{U}{(1-\alpha)}\left[\alpha-\left(\frac{a}{r}\right)^{3}\right] \cos \theta, \\
V_{\theta}=-\frac{\partial \phi}{r \partial \theta}=\frac{U}{(1-\alpha)}\left[\alpha+\frac{1}{2}\left(\frac{a}{r}\right)^{3}\right] \sin \theta,
\end{gathered}
$$




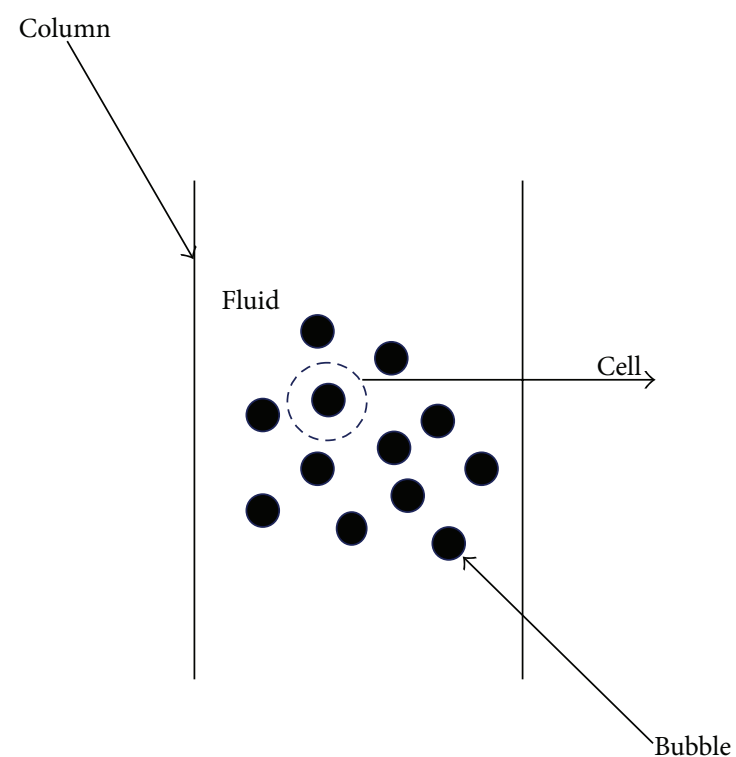

(a)

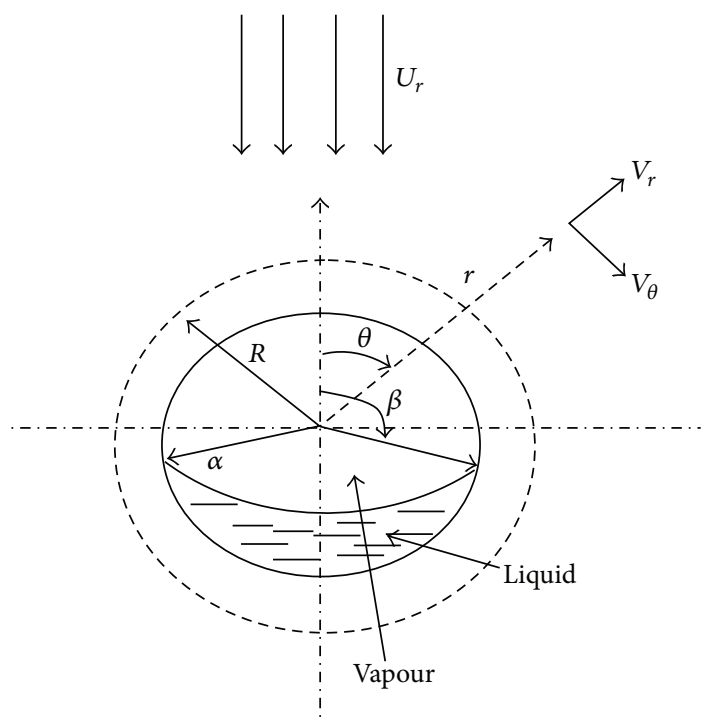

(b)

FIGURE 1: Schematic representation of the cell model.

where $V_{r}$ and $V_{\theta}$ are the radial and tangential velocity components.

Equations in (22) are different from these equations used by Marrucci [20] and Kendoush [21,22] when they analysed the problem of gas bubble swarm, which might lead to an error in their results.

Using a method similar to that suggested by Kendoush $[21,22]$, the drag force acting of the drops swarm evaporating in an immiscible liquid has been found by Mahood [12] as

$$
F_{D}=-8 \pi \mu a U f(\alpha) f(\mu) f_{\mathrm{Re}},
$$

where

$$
\begin{gathered}
f(\alpha)=\frac{(\alpha+0.5)}{(1-\alpha)^{2}}, \\
f(\mu)=\frac{3 \mu_{i}+2 \mu_{o}}{2\left(\mu_{i}+\mu_{o}\right)}, \\
f_{\operatorname{Re}}=1+0.15 \operatorname{Re}^{0.687},
\end{gathered}
$$

and the drag coefficient is

$$
C_{D}=\frac{48}{\operatorname{Re}} \frac{(\alpha+0.5)}{(1-\alpha)^{2}}\left(1+0.15 \operatorname{Re}^{0.687}\right) .
$$

The power of both drag force and buoyancy force should be equal to the rate of the total kinetic energy [23]

$$
\begin{aligned}
\left(F_{B}+F_{D}\right) U & =\frac{d}{d t}(K \cdot E) \\
& =\left(M+\bar{m} C_{v}\right) U \frac{d U}{d t},
\end{aligned}
$$

where the term $\left(\bar{m} C_{v}\right)$ denotes the added mass, which is derived for a swarm of spherical vapour bubbles evaporation in an immiscible liquid medium by Mahood [12] and Mahood et al. [24] as

$$
\bar{M}=\bar{m} C_{v}=\frac{4}{3} \pi \rho_{c} a^{3} \frac{f_{1}(\alpha)}{(1-\alpha)^{2}},
$$

where

$$
f_{1}(\alpha)=\frac{1}{2}+\frac{1}{2} \alpha-\alpha^{2}
$$

And $F_{B}$ is the buoyancy force, which can be written as:

$$
F_{B}=\frac{4}{3} \pi a^{3}(1-\alpha) \rho_{c} g
$$

Substituting (23) and (29) into (26), and ignoring bubbles mass, in comparison with added mass that is, $M \ll \bar{m} C_{v}$, (26) becomes

$$
g \frac{(1-\alpha)}{f_{2}(\alpha)}-\frac{6}{\rho_{c} a^{2}} \mu U \frac{f(t)}{f_{2}(\alpha)}=\frac{d U}{d t},
$$

where

$$
\begin{gathered}
f_{2}(\alpha)=\frac{f_{1}(\alpha)}{(1-\alpha)^{2}}=\frac{0.5+0.5 \alpha-\alpha^{2}}{(1-\alpha)^{2}}, \\
f(t)=f(\alpha) f(\mu) f_{\operatorname{Re}}
\end{gathered}
$$

Equation (30) can be solved in a similar way to Joseph's [23] and Concha's [25], which results in

$$
\begin{aligned}
U= & \frac{g(1-\alpha) \rho_{c} a^{2}}{6 \mu f(t)} \\
& \times\left[1-\exp \left(-\frac{6 \mu}{\rho_{c} a^{2}} \cdot \frac{f(t)}{f_{2}(\alpha)} \cdot t\right)\right] .
\end{aligned}
$$




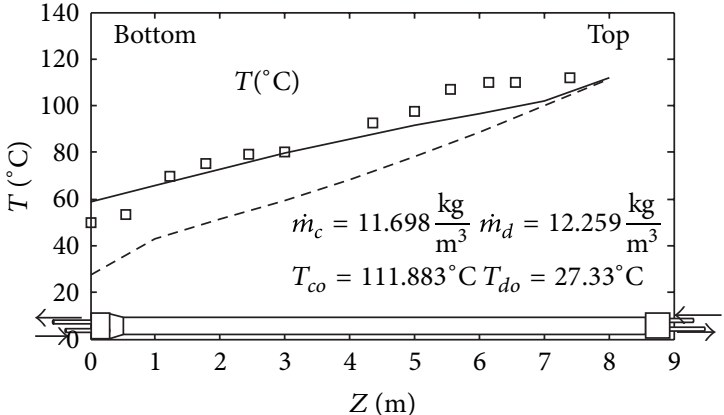

(a)

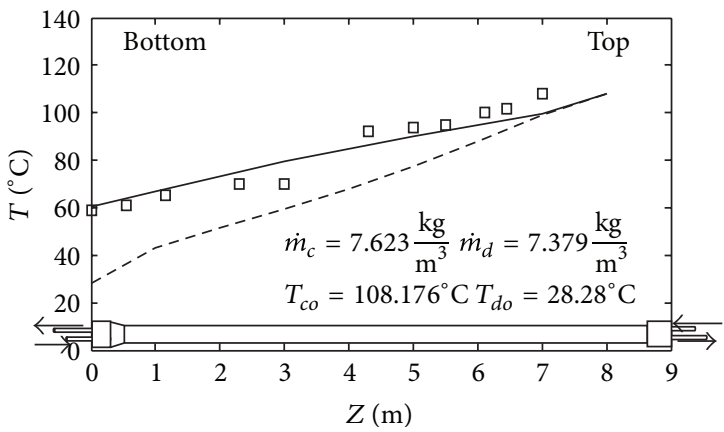

(c)

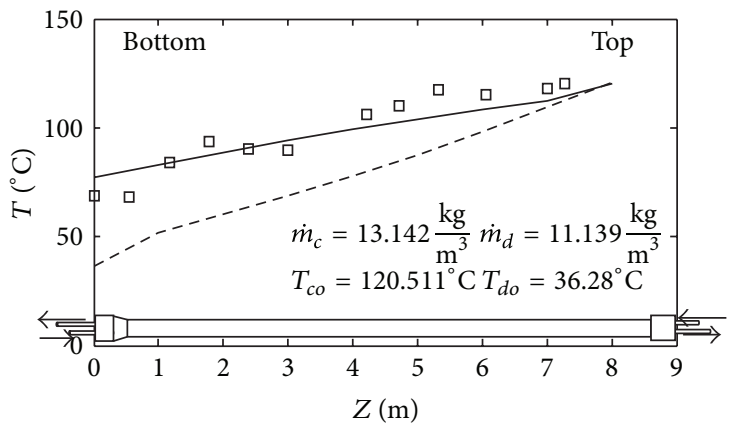

(e)

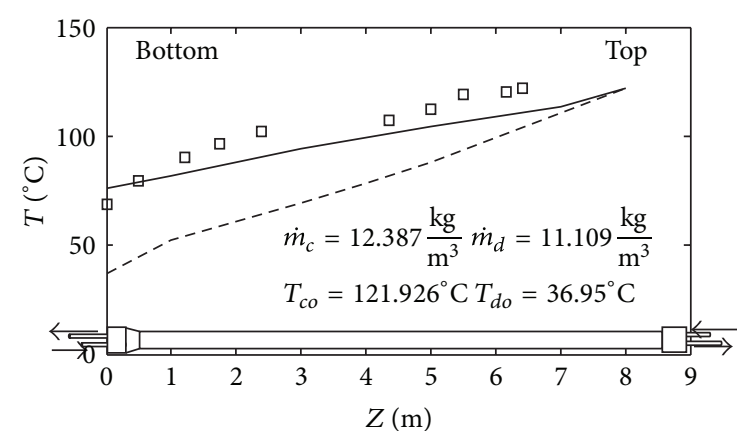

(b)

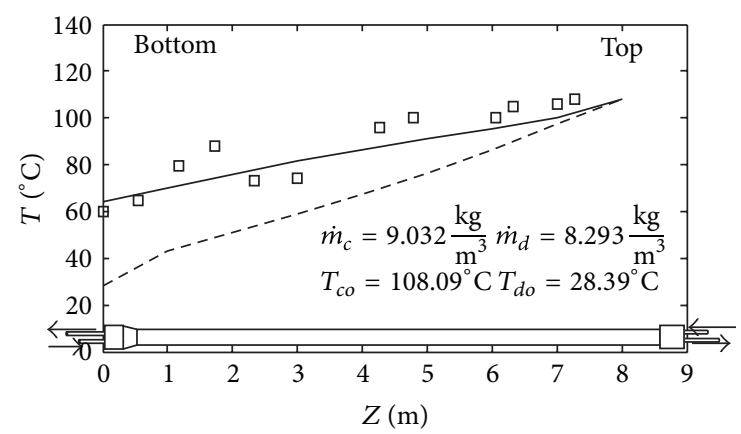

(d)

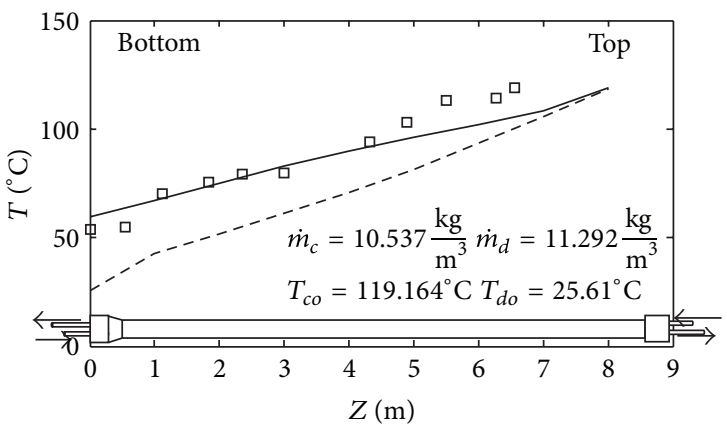

(f)

FIgURE 2: The variation in continuous phase (-) and dispersed phases (- - -) temperatures with direct contact heat exchanger height for $a=2 \mathrm{~mm}$.

For steady-state velocity or terminal velocity, with assuming a drop with a rigid wall due to the contiments, which leads to $f(\mu)=3 / 2$, (33) becomes

$$
U=\frac{g \rho_{c} a^{2}}{9 \mu f_{\mathrm{Re}}} \frac{(1-\alpha)^{3}}{(\alpha+0.5)}
$$

For $\alpha \rightarrow 0$, (34) reduces to an equation for a single drop as

$$
U(o)=\frac{2 g \rho_{c} a^{2}}{9 \mu f_{\mathrm{Re}}} .
$$

The ratio of bubbles warm velocity to the single bubble velocity can be found as:

$$
\frac{U(\alpha)}{U(o)}=\frac{1}{2}\left[\frac{(1-\alpha)^{3}}{(\alpha+0.5)}\right]
$$

Or

$$
U_{r}=\frac{U(o)}{2}\left[\frac{(1-\alpha)^{3}}{(\alpha+0.5)}\right] .
$$

Equation (15), now, can be written in terms of the heat transfer coefficient and the relative phases velocity as

$$
h=\frac{2 \sqrt{2}}{\sqrt{6 \pi}} \frac{k_{c} \beta^{0.5}}{\sqrt{a}}\left(\frac{U_{r}}{\epsilon} k_{v}\right)^{0.5},
$$

where

$$
\begin{gathered}
\mathrm{Nu}=\frac{2 a h}{k_{c}}, \\
\mathrm{Pe}=\left(\frac{2 a U_{r}}{\epsilon}\right) .
\end{gathered}
$$




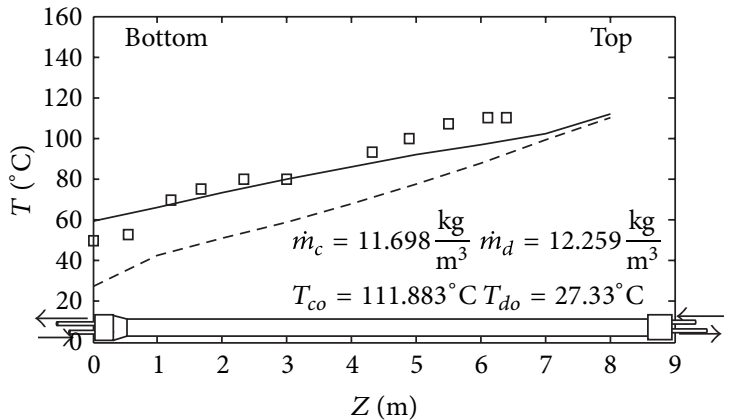

(a)

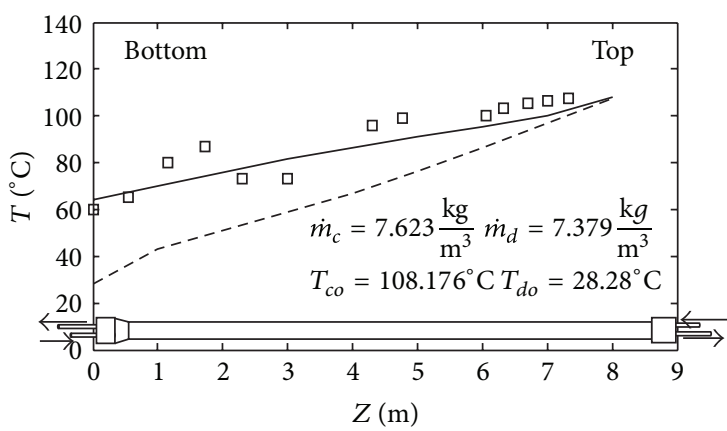

(c)

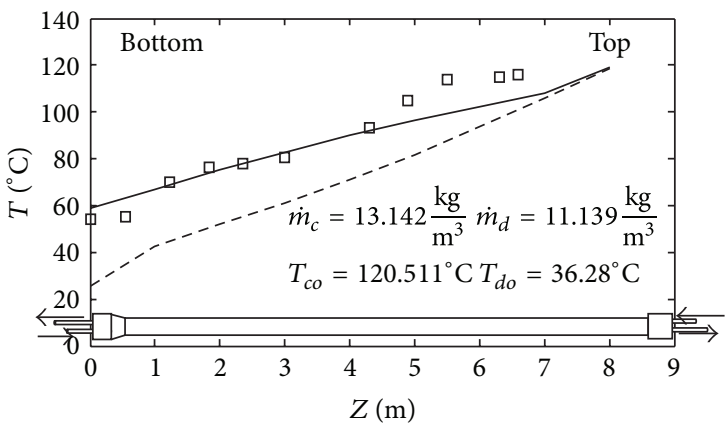

(e)

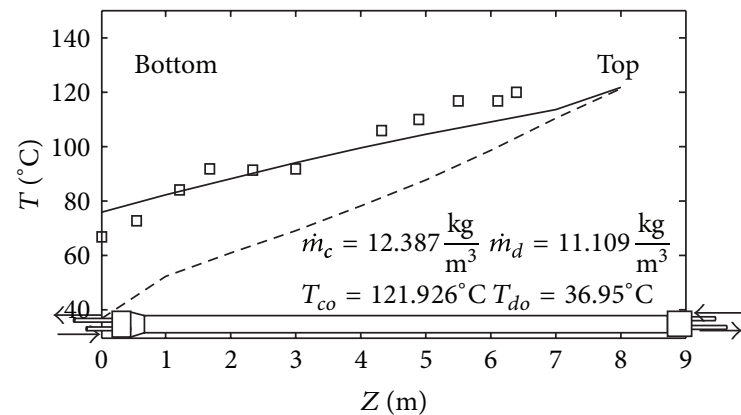

(b)

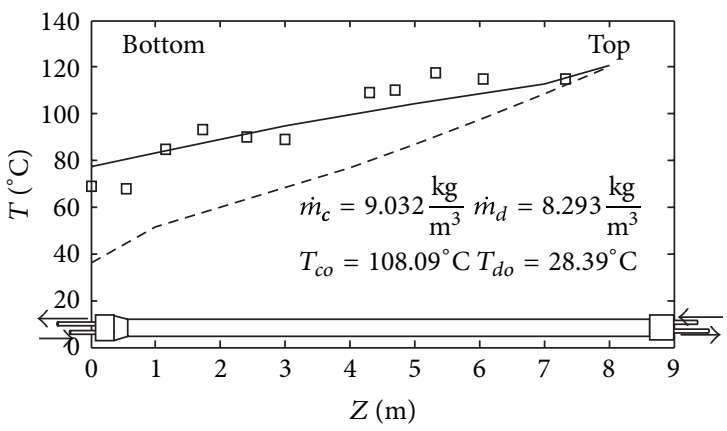

(d)

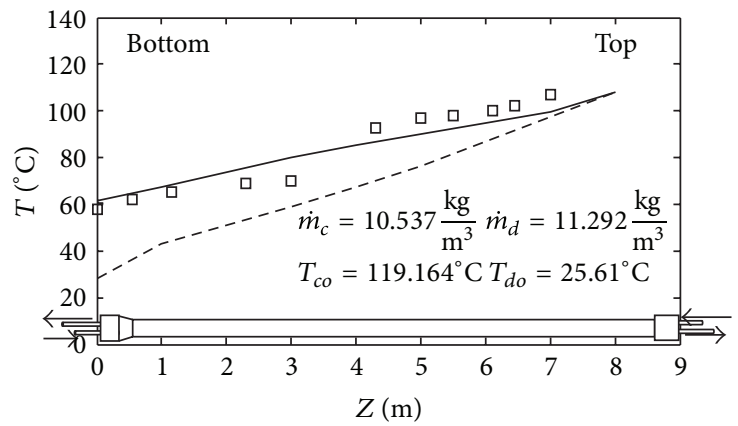

(f)

FIGURE 3: The variation in continuous phase (-) and dispersed phases (- - -) temperatures with direct contact heat exchanger height for $a=1.6 \mathrm{~mm}$

Using (37), (38) converts to

$$
h=\frac{2 k_{c}}{\sqrt{6 \pi}}\left(\frac{\beta U(o)}{a \epsilon} k_{v}\right)^{0.5}\left(\frac{(1-\alpha)^{3 / 2}}{(\alpha+0.5)^{1 / 2}}\right) .
$$

The evaporating drop radius is time dependent and can be found using the simple relation given by Wanchoo and Rina [26] as follows:

$$
a=a_{o}(1+x(s-1))^{1 / 3},
$$

where $x$ and $s$ denote the vaporization ratio and the dispersed phase liquid density, to its vapour density respectively.
Substituting (41) into (40) and substituting the result into (14), then substituting the result of this into (12) and (13) after completing the integration we obtain the following

$T_{c}=T_{c o}$

$$
-\left[\left(\frac{12}{\sqrt{6 \pi}}\right)\left(\frac{\alpha k_{c} A \Delta T}{d \dot{m}_{c} c_{p c}}\right)\left(\frac{\beta U_{o}}{a \epsilon}\right)^{0.5}\left(\frac{(1-\alpha)^{3 / 2}}{(\alpha+0.5)^{1 / 2}}\right) \cdot z\right],
$$

$$
\begin{aligned}
T_{d}= & T_{d o} \\
& +\left[\left(\frac{12}{\sqrt{6 \pi}}\right)\left(\frac{\alpha k_{c} A \Delta T}{d \dot{m}_{d} c_{p d}}\right)\left(\frac{\beta U_{o}}{a \epsilon}\right)^{0.5}\left(\frac{(1-\alpha)^{3 / 2}}{(\alpha+0.5)^{1 / 2}}\right) \cdot z\right] .
\end{aligned}
$$




\section{Results and Discussion}

The analytical results for temperatures distribution of both dispersed and continuous phases along the spray column in the direct contact heat exchanger are compared with the experimental data given by Olander et al. [27] to verify the theoretical model results. According to (42) and (43), only the initial phases temperatures and mass flow rates are needed to obtain the temperature distribution along the spray column, assuming a value for holdup ratio within the range calculated by Golafshani [28]. He mentioned that the holdup ratio increases very slowly inside the column due to increasing drop diameters, which is assumed to be a constant through his numerical analysis. In fact, the range of the holdup ratio increase was from 0.14 to 0.165 only. In current analysis, the drop diameters taken as a variable depend on the vaporization rate or the ratio inside the drop. Accordingly, and because of unavailable expression being available to describe this factor during the evaporation of drops or condensation of bubbles in an immiscible liquid, the experimental data was fitted to that given by Sideman and Hirsch [29], which was for a two-phase bubble condensation in an immiscible liquid media. Sideman and Hirsch [29] and others found much similarity in the heat transfer mechanism between the cases of evaporation drops and condensation bubbles in immiscible liquid media.

Figures 2 and 3 show the variation of dispersed and continuous phase temperatures and the spray column height at different initial phases temperatures and flow rates, with an initial drop radius equal to $2 \mathrm{~mm}$ and $1.6 \mathrm{~mm}$. It can be clearly seen, that three visible regions appear on these figures, which agrees with [1]. The first region is at the phases' entrance, where the temperature difference is at its maximum between the phases. In this region a high increase in dispersed temperature occurs, while nearly a constant temperature in the continuous phase. This zone covers a very short length of the column (about $1 \mathrm{~m}$ ), and it seems independent of the operational column parameters.

The second zone starts after nearly one metre of the column height and has a slow heat exchange between the phases. According to the results, it seems to cover a wide range of the column height. The final zone, which represents the last opportunity for heat exchange, and at this region the temperature difference decreases to minimum. Therefore, it seems to be an extension of the second region effect.

From the results, good agreement seem to have been achieved between the analytical model results and the experimental results of Olander et al. [27] for all figures. The main reason or the divergence in the results of the dispersed phase from the experimental data is that the devices basically measuring the water (continuous phase) temperature instead of the dispersed (two-phase bubbles). Therefore, sometime an averaging technique is used to obtain the mixed temperature [8].

In addition, the maximum divergence between the present analytical model and the experimental data occurs at the bottom of the column especially when the dispersed phase is injected bellow the saturation temperature. In this case the evaporation delayed as drops would need to reach their saturation temperature before the evaporation starts, meaning that heat will be consumed within the drops. The maximum error in this region is nearly $12.18 \%$.

\section{Conclusions}

An analytical model has been developed for the temperature distribution of a spray-column, three-phase direct contact heat exchanger. According to the model developed in this work, we have shown that it is reasonable to assume a constant holdup ratio along the direct contact column, which is in accordance with other numerical models in the literature such as Cabon and Boehm [8], Jacobs and Golafshani [9], and Kang et al. [11]. Even more, it has been shown that the vaporization ratio of drops is an influential parameter in the heat exchange process. As expected, we have proved that the rate of heat transfer increases with decreasing drops size. Since our model correlated well with experimental results in the literature (e.g., Olander et al. [28]) we expect that this model will enhance optimisation of practical applications in areas such as the production of electrical power from geothermal hot brine, extracting energy from salt gradient solar pond, and the process of heating water by heat collecting working fluids.

\section{Nomenclatures}

\begin{tabular}{ll}
$A:$ & Area $\left(\mathrm{m}^{2}\right)$ \\
$a:$ & Drop radius $(\mathrm{m})$ \\
$a_{o}:$ & Initial drops radius $(\mathrm{m})$ \\
$C_{D}:$ & Drag coefficient \\
$c_{p c}:$ & Specific heat of continuous phase \\
& $\left(\mathrm{kJ} \cdot \mathrm{kg}^{-1} \cdot \mathrm{K}^{-1}\right)$ \\
$c_{p d}:$ & Specific heat of dispersed phase \\
& $\left(\mathrm{kJ} \cdot \mathrm{kg}^{-1} \cdot \mathrm{K}^{-1}\right)$ \\
$C_{v}:$ & Virtual mass coefficient \\
$d:$ & Column diameter $(\mathrm{m})$ \\
$f(t):$ & Function appearing in $(32)$ \\
$f(\alpha):$ & Function appearing in $(24)$ \\
$f_{1}(\alpha):$ & Function appearing in $(28)$ \\
$f_{2}(\alpha):$ & Function appearing in $(31)$ \\
$F_{B}:$ & Buoyancy force $(\mathrm{N})$ \\
$F_{D}:$ & Drag force $(\mathrm{N})$ \\
$g:$ & Acceleration of gravity $\left(\mathrm{m} \cdot \mathrm{s}^{2}\right)$ \\
$k_{c}:$ & Thermal conductivity of continuous \\
& phase $\left(\mathrm{W} \cdot \mathrm{m}^{-1} \cdot \mathrm{K}^{-1}\right)$ \\
$h:$ & Heat transfer coefficient \\
& $\left(\mathrm{kJ} \cdot \mathrm{m}^{2} \cdot \mathrm{s}^{-1} \cdot \mathrm{K}^{-1}\right)$ \\
$h_{c}:$ & Enthalpy of continuous phase $\left(\mathrm{kJ} \cdot \mathrm{kg}^{-1}\right)$ \\
$h_{d}:$ & Enthalpy of dispersed phase $\left(\mathrm{kJ} \cdot \mathrm{kg}^{-1}\right)$ \\
$M:$ & Mass of drop $(\mathrm{kg})$ \\
$\dot{m}_{c}:$ & Continuous phase mass flow rate \\
$\dot{m}_{d}:$ & (kg $\left.\cdot \mathrm{s}^{-1}\right)$ \\
\hline$M:$ & Dispersed phase mass flow rate $\left(\mathrm{kg}^{-1} \mathrm{~s}^{-1}\right)$ \\
& Virtual mass $(\mathrm{kg})$
\end{tabular}


$\bar{m}: \quad$ Mass of fluid displaced by drops ( $\mathrm{kg}$ )

Nu: Nusselt number

Pe: Péclet number

Q: $\quad$ Heat transfer $(W)$

Re: Reynolds number

$U: \quad$ Velocity $\left(\mathrm{m} \cdot \mathrm{s}^{-1}\right)$

$U_{r}: \quad$ Relative velocity

$U(o)$ : Single drop velocity $\left(\mathrm{m} \cdot \mathrm{s}^{-1}\right)$

$U(\alpha)$ : Velocity of drops swam $\left(\mathrm{m} \cdot \mathrm{s}^{-1}\right)$

$s: \quad$ Density ratio (dispersed phase vapour density to the its liquid density)

$T_{c}: \quad$ temperature of continuous phase $(\mathrm{C})$

$T_{d}: \quad$ Temperature of dispersed phase ( $(\mathrm{C})$

$\Delta T: \quad$ Temperature differences $\left({ }^{\circ} \mathrm{C}\right)$

$V_{r}: \quad$ Radial velocity component $\left(\mathrm{m} \cdot \mathrm{s}^{-1}\right)$

$V_{\theta}$ : Tangential velocity component $\left(\mathrm{m} \cdot \mathrm{s}^{-1}\right)$

$x$ : $\quad$ Vaporization ratio

$z: \quad$ Height $(\mathrm{m})$.

\section{Greek Symbols}

$\rho_{c}$ : Continuous phase density $\left(\mathrm{kg} \cdot \mathrm{m}^{-3}\right)$

$\rho_{d}$ : Dispersed phase density $\left(\mathrm{kg} \cdot \mathrm{m}^{-3}\right)$

$\alpha$ : Holdup ratio

$\mu$ : Dynamic viscosity of continuous phase $\left(\mathrm{N} \cdot \mathrm{s} \cdot \mathrm{m}^{2}\right)$

$\epsilon$ : Thermal diffusivity $\left(\mathrm{m}^{2} \cdot \mathrm{s}^{-1}\right)$.

\section{Subscript}

$o$ : Initial.

\section{References}

[1] L. Tadrist, P. Seguin, R. Santini, J. Pantaloni, and A. Bricard, "Experimental and numerical study of direct contact heat exchangers," International Journal of Heat and Mass Transfer, vol. 28, no. 6, pp. 1215-1227, 1985.

[2] M. Song, A. Steiff, and P. M. Weinspach, "Direct-contact heat transfer with change of phase: a population balance model," Chemical Engineering Science, vol. 54, no. 17, pp. 3861-3871, 1999.

[3] Z. Peng, W. Yiping, G. Cuili, and W. Kun, "Heat transfer in gasliquid-liquid three-phase direct-contact exchanger," Chemical Engineering Journal, vol. 84, no. 3, pp. 381-388, 2001.

[4] F. Dammel and H. Beer, "Heat transfer from a continuous liquid to an evaporating drop: a numerical analysis," International Journal of Thermal Sciences, vol. 42, no. 7, pp. 677-686, 2003.

[5] S. Sideman and Y. Gat, "Direct contact heat transfer with change of phase: spray column studies of a three-phase heat exchanger," AIChE Journal, vol. 12, no. 2, pp. 296-303, 1966.

[6] R. Letan and E. Kehat, "The mechanism of heat transfer in spray column heat exchanger," AIChE Journal, vol. 14, no. 3, pp. 398405, 1968.

[7] S. B. Plass, H. R. Jacobs, and R. F. Boehm, "Operational characteristics of spray column type direct contact preheater," AIChE Symposium Series-Heat Transfer, vol. 75, no. 189, pp. 227-234, 1979.

[8] T. Coban and R. Boehm, "Performance of a three-phase, spray-column, direct-contact heat exchanger," Journal of Heat Transfer, vol. 111, no. 1, pp. 166-172, 1989.
[9] H. R. Jacobs and M. Golafshani, "Heuristic evaluation of the governing mode of heat transfer in a liquid-liquid spray column," Journal of Heat Transfer, vol. 111, no. 3, pp. 773-779, 1989.

[10] R. A. Brickman and R. F. Boehm, "Maximizing three-phase direct-contact heat exchanger output," Numerical Heat Transfer A, vol. 26, no. 3, pp. 287-299, 1994.

[11] Y. H. Kang, N. J. Kim, B. K. Hur, and C. B. Kim, "A numerical study on heat transfer characteristics in a spray column direct contact heat exchanger," KSME International Journal, vol. 16, no. 3, pp. 344-353, 2002.

[12] H. B. Mahood, "Theoretical modelling of three-phase direct contact spray column heat exchanger," AMPhil-PhD Transfer Report, University of Surrey, 2012.

[13] J. Isenberg and S. Sideman, "Direct contact heat transfer with change of phase: bubble condensation in immiscible liquids," International Journal of Heat and Mass Transfer, vol. 13, no. 6, pp. 997-1011, 1970.

[14] D. Moalem, S. Sideman, A. Orell, and G. Hetsroni, "Direct contact heat transfer with change of phase: condensation of a bubble train," International Journal of Heat and Mass Transfer, vol. 16, no. 12, pp. 2305-2319, 1973.

[15] D. Moalem-Maron, M. Sokolov, and S. Sideman, "A closed periodic condensation-evaporation cycle of an immiscible, gravity driven bubble," International Journal of Heat and Mass Transfer, vol. 23, no. 11, pp. 1417-1424, 1980.

[16] L. M. Milne-Thomson, Theoretical Hydrodynamics, Macmilan, London, UK, 5th edition, 1972.

[17] X. Cai and G. B. Wallis, "A more general cell model for added mass in two-phase flow," Chemical Engineering Science, vol. 49, no. 10, pp. 1631-1638, 1994.

[18] H. Lamb, Hydrodynamics, Cambridge University Press, 6th edition, 1932.

[19] A. A. Kendoush, "Theory of convective drop evaporation in direct contact with an immiscible liquid," Desalination, vol. 169, no. 1, pp. 33-41, 2004.

[20] G. Marrucci, "Rising velocity of a swarm of spherical bubbles," Industrial and Engineering Chemistry Fundamentals, vol. 4, no. 2, pp. 224-225, 1965.

[21] A. A. Kendoush, "Hydrodynamic model for bubbles in a swarm," Chemical Engineering Science, vol. 56, no. 1, pp. 235238, 2001.

[22] M. Worner, "A compact introduction to the numerical modelling of multiphase flow," Forschungszentrum Karlrsruhe, Wissenschaftliche Berichte FZKA 6932, 2003.

[23] D. D. Joseph, "Potential flow of viscous fluids: historical notes," International Journal of Multiphase Flow, vol. 32, no. 3, pp. 285310, 2006.

[24] H. B. Mahood, A. Sharif, S. A. Hossini, and R. Thorpe, "Hydrodynamics of two-phase bubbles condensation in an immiscible liquid media," In press.

[25] F. Concha, "Settling velocities of particulate systems," Kona Powder and Particle Journal, vol. 27, pp. 18-37, 2009.

[26] R. K. Wanchoo and G. K. Raina, "Motion of a two-phase bubble through a quiescent liquid," The Canadian Journal of Chemical Engineering, vol. 65, no. 5, pp. 716-722, 1987.

[27] R. Olander, S. Oshmyansku, K. Nichols, and D. Werner, "Final phase testing and evaluation of the $500 \mathrm{kWe}$ direct contact pilot plant at East Mesa," U.S.D.O.E. Report DOE/SF/11700-T1, Arvada, Colo, USA, 1983. 
[28] M. Golafshani, Stability of a direct contact heat exchanger [Ph.D. thesis], University of Utah, 1984.

[29] S. Sideman and G. Hirsch, "Direct contact heat transfer with change of phase: condensation of a single vapour bubbles in an immiscible liquid medium: preliminary sui," AIChE Journal, vol. 11, no. 6, pp. 1019-1025, 1965. 

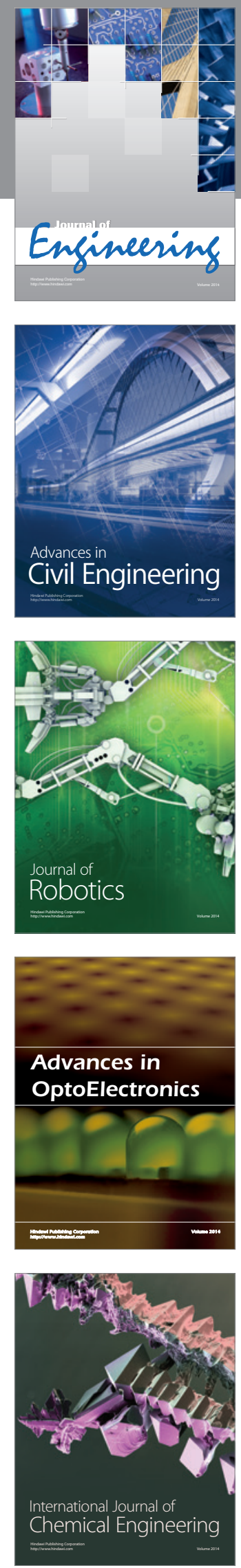

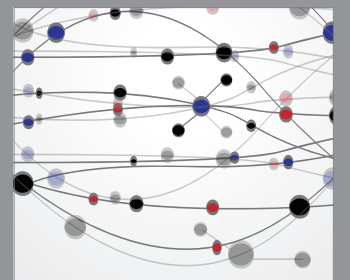

The Scientific World Journal
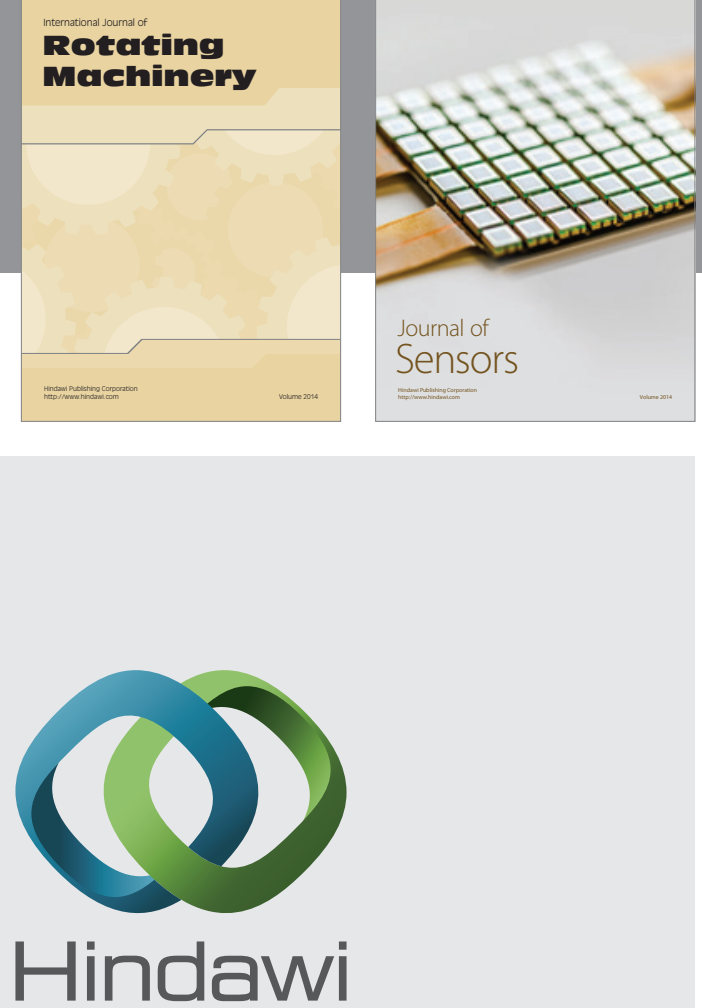

Submit your manuscripts at http://www.hindawi.com
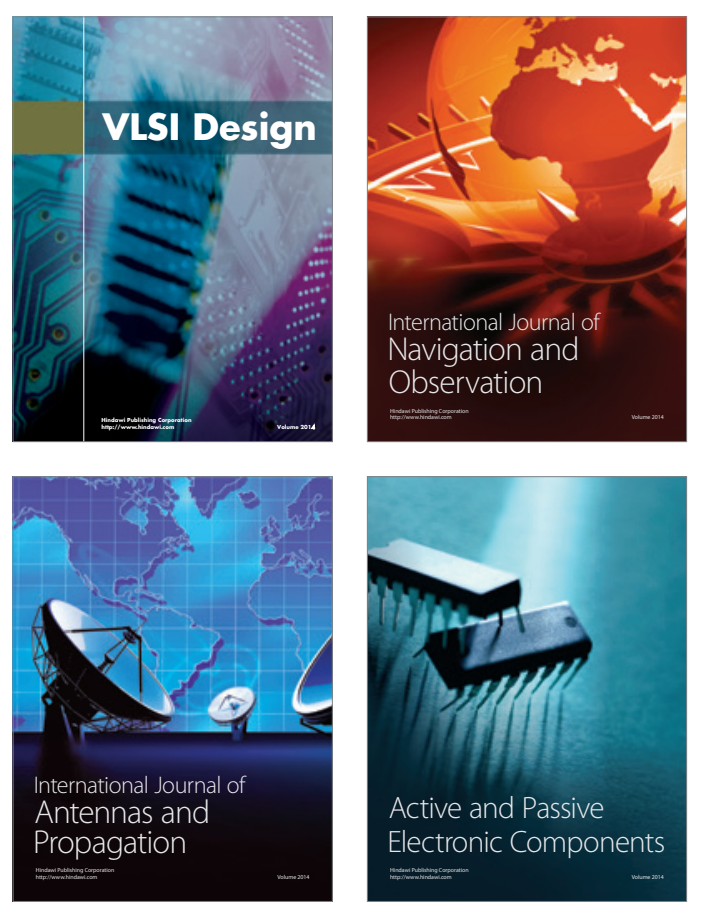
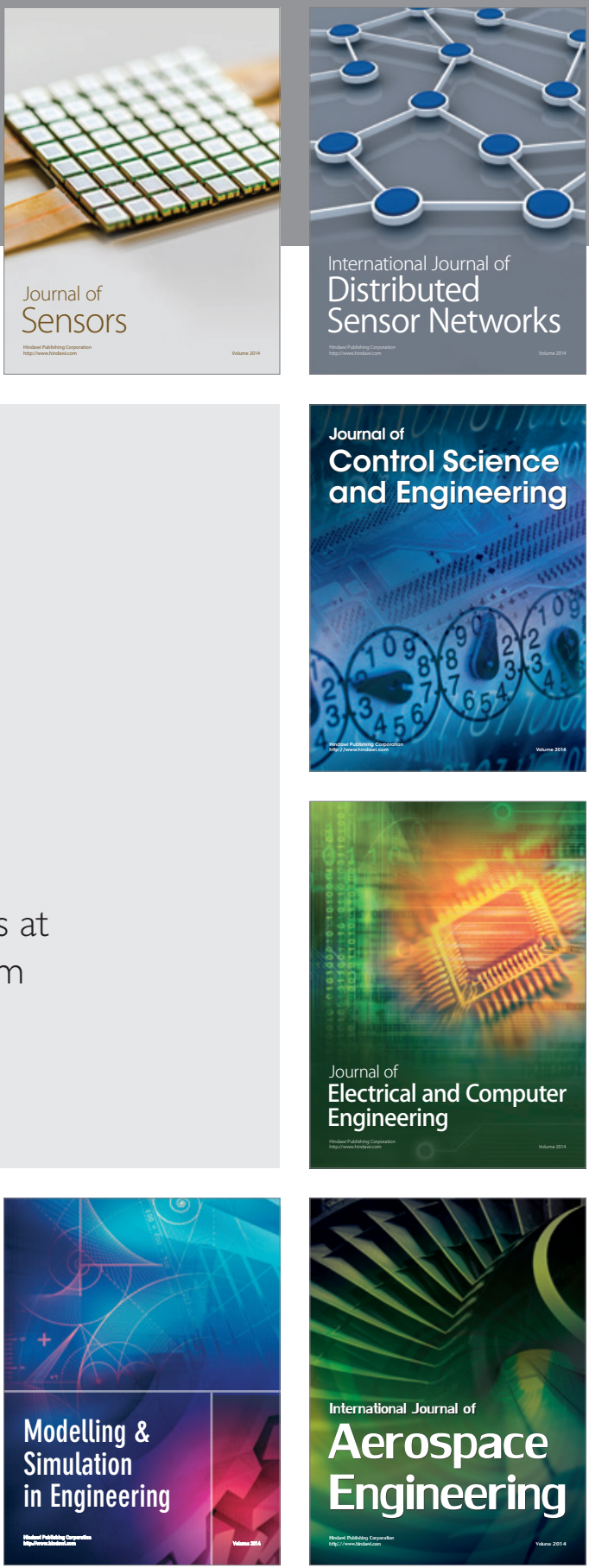

Journal of

Control Science

and Engineering
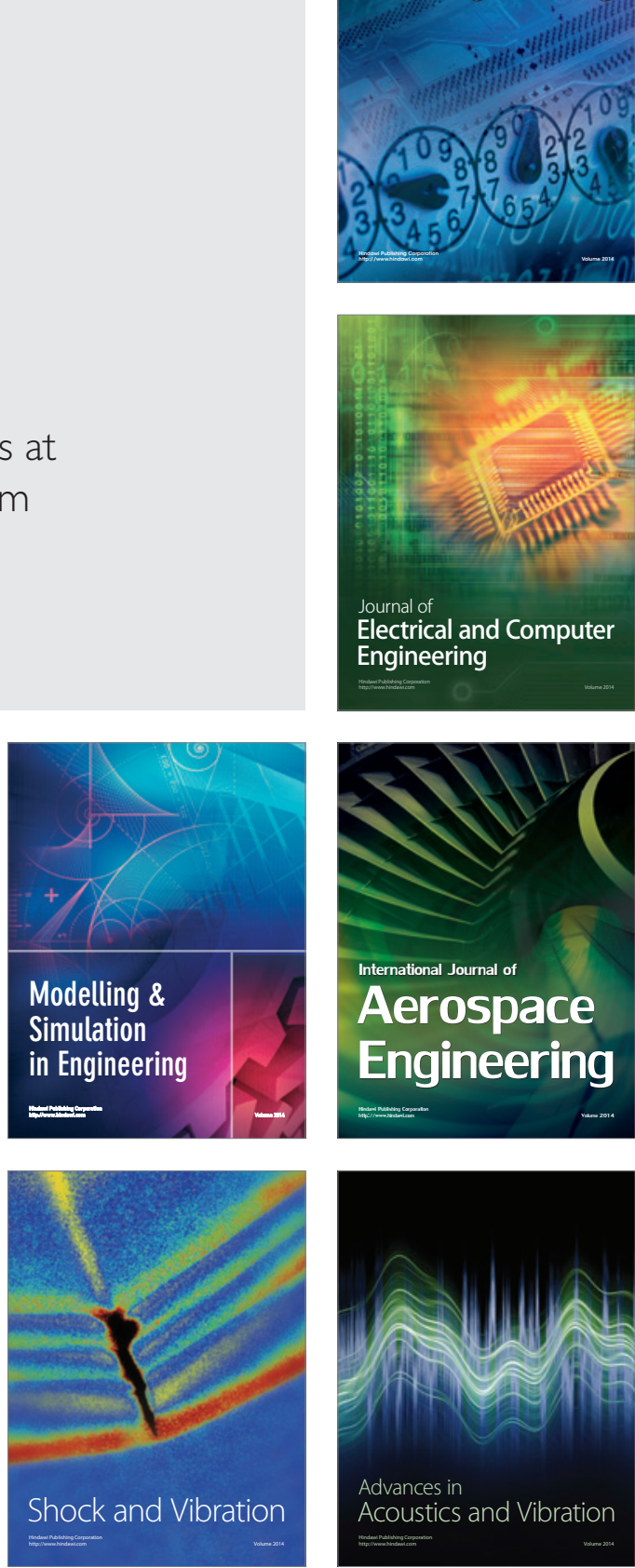